\title{
Transport of Carbon Dioxide through a Biomimetic Membrane
}

\author{
Efstathios Matsaridis, ${ }^{1}$ Varban Savov, ${ }^{1}$ Alexandre Gritzkov, ${ }^{1}$ \\ Nelie Zheleva, ${ }^{1}$ and Stoyan Gutzov ${ }^{2}$ \\ ${ }^{1}$ Faculty of Physics, Sofia University "St. Kliment Ohridski”, 5 James Bourchier Boulerard, 1164 Sofia, Bulgaria \\ ${ }^{2}$ Faculty of Chemistry, Sofia University “St. Kliment Ohridski”, 1 James Bourchier Boulerard, 1164 Sofia, Bulgaria \\ Correspondence should be addressed to Stoyan Gutzov, sgutzov@chem.uni-sofia.bg
}

Received 30 September 2010; Revised 15 June 2011; Accepted 5 July 2011

Academic Editor: Jan Skov Pedersen

Copyright (C) 2011 Efstathios Matsaridis et al. This is an open access article distributed under the Creative Commons Attribution License, which permits unrestricted use, distribution, and reproduction in any medium, provided the original work is properly cited.

\begin{abstract}
Biomimetic membranes (BMM) based on polymer filters impregnated with lipids or their analogues are widely applied in numerous areas of physics, biology, and medicine. In this paper we report the design and testing of an electrochemical system, which allows the investigation of $\mathrm{CO}_{2}$ transport through natural membranes such as alveoli barrier membrane system and also can be applied for solid-state measurements. The experimental setup comprises a specially designed two-compartment cell with BMM connected with an electrochemical workstation placed in a Faraday cage, two PH meters, and a nondispersive infrared gas analyzer. We prove, experimentally, that the $\mathrm{CO}_{2}$ transport through the natural membranes under different conditions depends on $\mathrm{pH}$ and displays a similar behavior as natural membranes. The influence of different drugs on the $\mathrm{CO}_{2}$ transport process through such membranes is discussed.
\end{abstract}

\section{Introduction}

Nitrocellulose filters impregnated with fatty acids and their esters are suitable for modeling of many physicochemical properties of natural biomembranes, including selective barrier properties [1-10]. Such properties are connected both with the presence of a nitrocellulose matrix with fixed cationexchange groups in the pores impregnated with lecithin and their interaction with water molecules. The similarity of several physical properties of impregnated nitrocellulose filters and biomembranes is determined by the simultaneous coexistence of polymer matrixes with immobilized cationexchange groups and pores, whose surface is covered with a thin layer of water while they are filled with liquid crystal of lipid-like substances.

In this paper we demonstrate experimentally that carbon dioxide transport through BMM membranes depends on $\mathrm{pH}$ using an electrochemical setup combined with two $\mathrm{pH}$ meters and an IR-gas analyzer. The interest in this problem is related to the $\mathrm{CO}_{2}$ and $\mathrm{O}_{2}$ exchange in biological membranes of the blood system.

In animal with lungs, the bicarbonate buffer system is an effective physiological buffer with $\mathrm{pH}=7.4$, because
$\mathrm{H}_{2} \mathrm{CO}_{3}$ of blood plasma is in equilibrium with a large reserve capacity of $\mathrm{CO}_{2}$ in the air space of the lungs. This buffer system involves three reversible equilibria between gaseous $\mathrm{CO}_{2}$ in the lungs and bicarbonate $\left(\mathrm{HCO}_{3}{ }^{-}\right)$in the blood plasma (Figure 1) [11-16]. On Figure 2 a SEM picture of a nonimpregnated membrane is given.

\section{Materials and Methods}

Millipore nitrocellulose membrane filters (average pore diameter about $8 \mu \mathrm{m}$; Ireland, Millipore Cat no. SCWP04700) impregnated with $320 \mathrm{mg} / \mathrm{mL}$ Lecithine (Sigma Aldrich) in n-tetradecane (Sigma Aldrich; surface area $172 \mathrm{~mm}^{2}$ and thickness $100-120 \mu \mathrm{m}$, Figure 2), were placed between two compartments (chambers, half-cells) made of Plexiglas (LI and RI). At the opposite side each chamber possesses $\mathrm{Ag} / \mathrm{AgCl}, \mathrm{Au}$, and Pt electrodes (Figure 3). Both chambers were filled with $\mathrm{KCl} 10^{-1} \mathrm{M}$. The whole membrane module was placed in a Faraday cage to prevent electromagnetic interferences. All measurements were performed at $36^{\circ} \mathrm{C}$ as the solutions were intensively stirred (agitated). The A.C. transmembrane impedance was measured before and after 


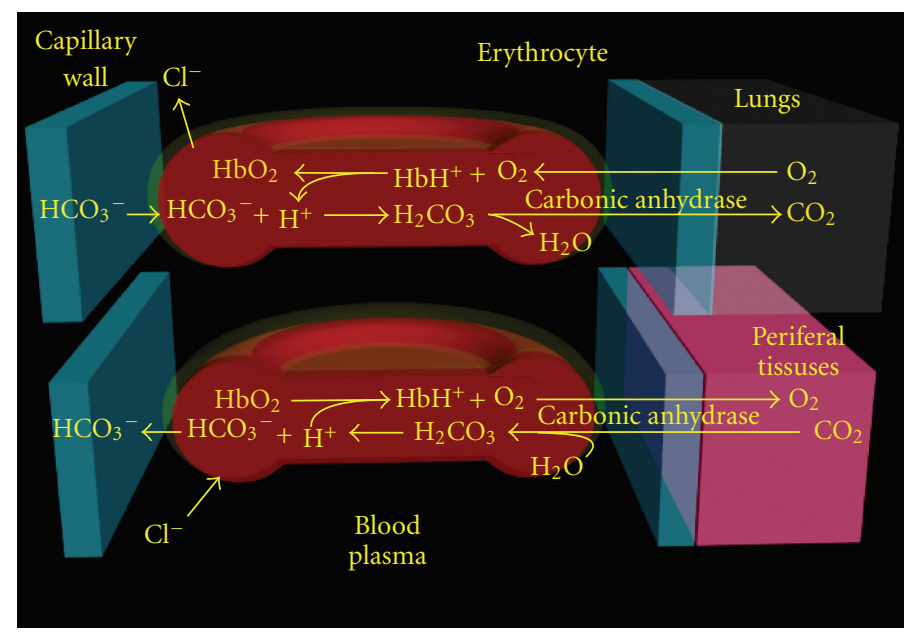

FIGURE 1: Relations between the respiration and blood plasma buffer system. Notations: $\mathrm{HbO}_{2}{ }^{-}, \mathrm{HbH}^{+}$.

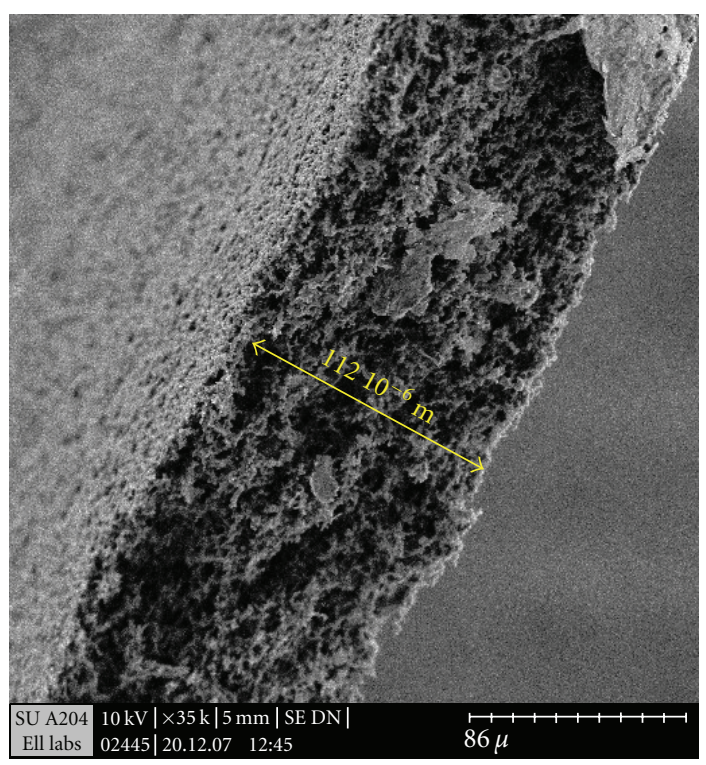

Figure 2: SEM image of a cross-section of the non-impregnated membrane, the yellow arrow indicates the thickness of the membrane.

every experimental step in a frequency range from $100 \mathrm{mHz}$ to $100 \mathrm{kHz}$ (signal amplitude applied to the membrane $50 \mathrm{mV})$ by an electrochemical workstation $\mathrm{CHI} 604(\mathrm{CH}$ Instruments Ltd., USA). The impedance was plotted in a complex plane (Nyquist Plot). SEM investigations of membranes are performed with a S-570 Hitachi microscope.

\section{Experimental Setup}

The left (LI) and right (RI) chambers were connected to other two thermostated glass chambers (LII \& RII) by silicon tubes. The solutions in the pairs (LI and LII, and RI and RII) compartments were driven to permanent circulation.

At the left chamber (LI) the $\mathrm{CO}_{2}$ dissolving was accomplished by gas bubbling (blowing) through the

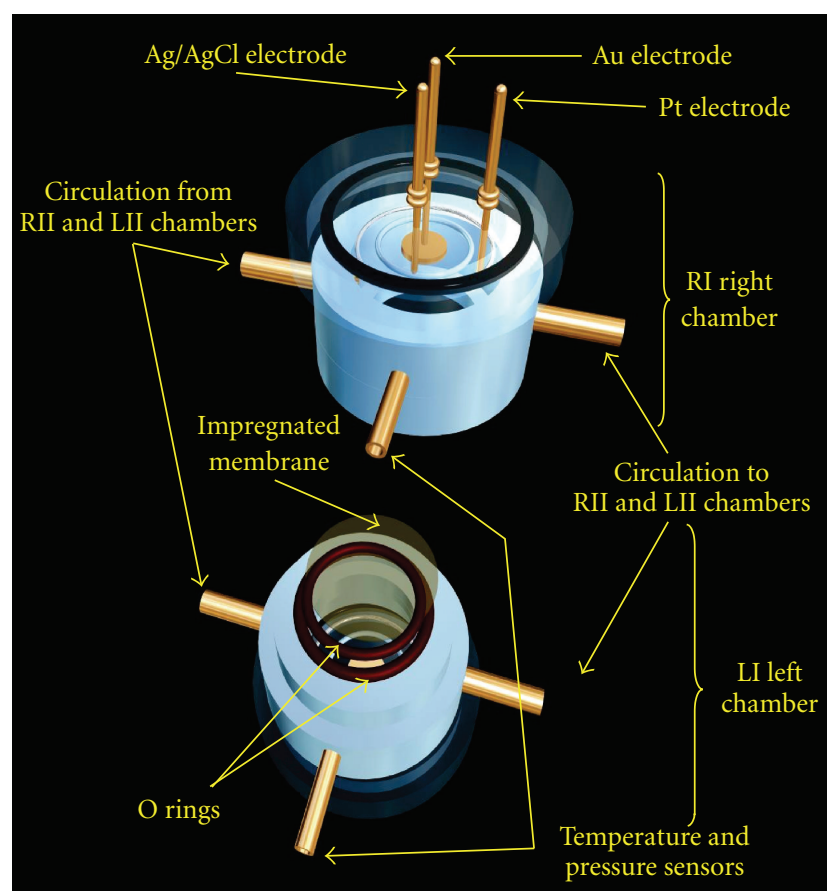

FIgURE 3: The biomimetic membrane divide LI \& RI chambers.

corresponding water solution. The process was controlled through $\mathrm{pH}$ measurements by a standard $\mathrm{pH}$ meter ( $\mathrm{pH} / \mathrm{mV} /$ Cond/Temp-meter 6350 Lasar Laboratories), connected to PC data acquisition station. $\mathrm{CO}_{2}$ passes through the membrane into RI compartment and, after the solution reaches the chamber RII, the other $\mathrm{pH}$ meter ( $\mathrm{pH} / \mathrm{mV} / \mathrm{ION} /$ Temp-meter 6250, Lasar Laboratories) registrates the changes of $\mathrm{pH}$ in right compartment. The $\mathrm{CO}_{2}$ gas-phase concentration in RII chamber arising due to its desorption from the solution was measured by nondispersive infra-red gas analyzer (model DX6210, RMT Ltd. accuracy 0,5\%, Figure 4). 


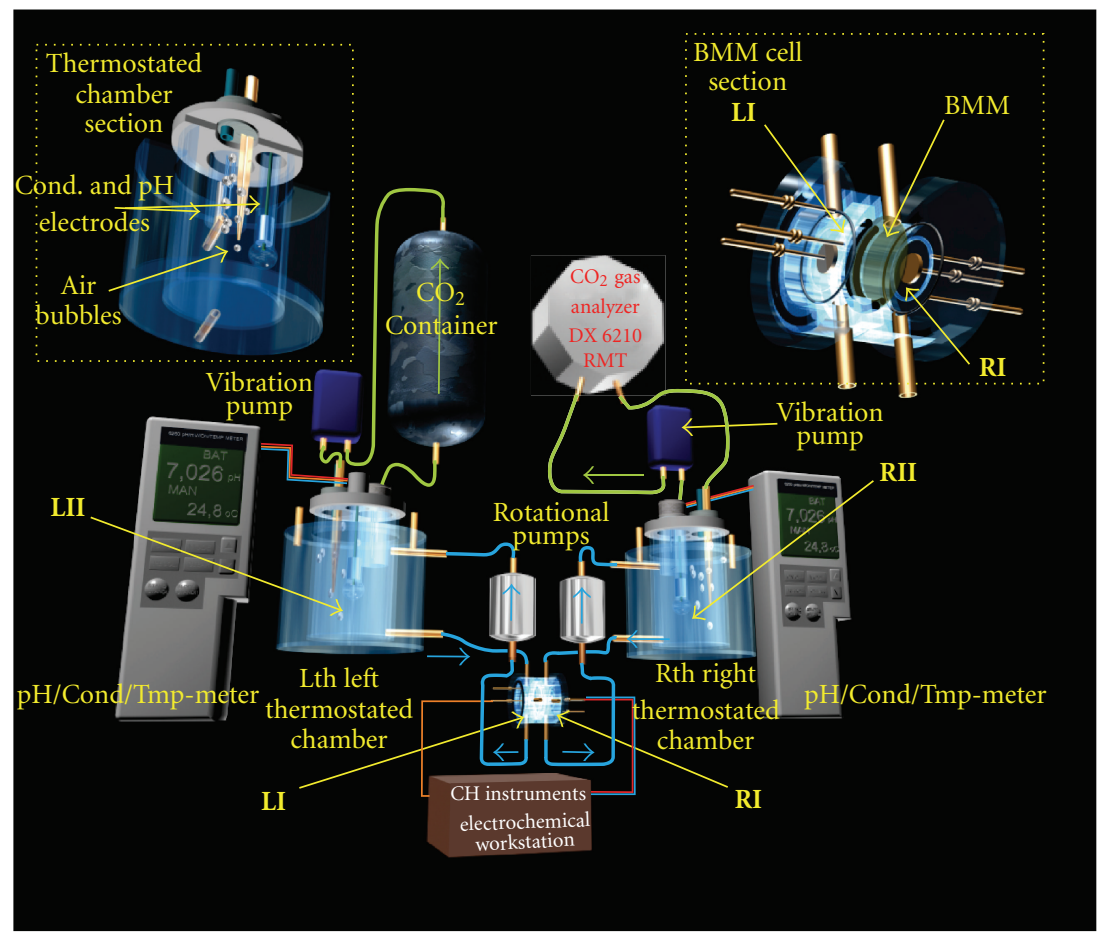

Figure 4: Block scheme of the experiment.

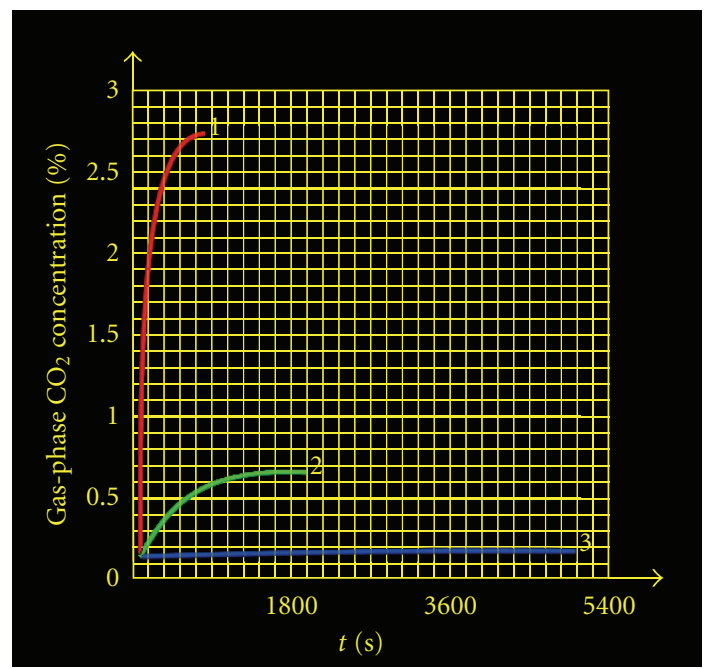

FIgURE 5: Change in $\mathrm{CO}_{2}$ concentration versus time. (1) Dry non impregnated membrane, empty chambers. (2) Nonimpregnated membrane, compartments filled with $0,1 \mathrm{M}$ of $\mathrm{KCl}$ solution. (3) Membrane impregnated with $320 \mathrm{mg} / \mathrm{mL}$ of lecithine in tetradecane solution, chambers filled with $0,1 \mathrm{M} \mathrm{KCl}$ solution.

\section{Experimental Results}

On Figure 5 the change of $\mathrm{CO}_{2}$ concentration versus time is demonstrated. BMM is a microheterogeneous structure consisting of polysaccharide matrix contained in fixed ionexchange groups. These groups interact with water molecules and impregnated lipid-like liquids. The influence of gas inclusions on the experimental data seems of no importance, because the total cross-section area at the membrane surface is less than $10 \%$ of the whole filter area. The data obtained prove that the $\mathrm{CO}_{2}$ transport depend on liquid impregnation and the mass transport can be controlled in this way.

The first experimental stage is measurements using a dry nonimpregnated membrane with empty compartments of the electrochemical cell. We depicted very short times necessary for $\mathrm{CO}_{2}$ to pass from LI into RI and then to RII chambers (Figure 5) compared to that measured under other conditions.

The same experimental procedure was applied to nonimpregnated filter membranes and LI, LII, RI, and RII chambers filled with $10^{-1} \mathrm{M} \mathrm{KCl}$ solution, and then to a lecithin-impregnated filter in the same solution (Figure 5). The results illustrates that the $\mathrm{CO}_{2}$ transport through BMM is a slow process compared to the transport through non impregnated filters. On Figure 6 the $\mathrm{CO}_{2}$ transport through an impregnated membrane is depicted in connection with our experimental data for $\mathrm{pH}$. The membrane filter used was impregnated with a lecithine solution in n-tetradecane with a concentration $320 \mathrm{mg} / \mathrm{mL}$.

The change in the gas phase carbon dioxide $\left(\mathrm{CO}_{2}\right)$ concentration in RII compartment is combined with changes in $\mathrm{pH}$ in $\mathrm{RI} / \mathrm{RII}$ chambers due to formation of carbonic acid. It is worthwhile to mention here that before and after each $\mathrm{CO}_{2}$ transport measurement, we have checked the membrane integrity by measuring their impedance (Figure 7).

From data depictured in Figure 6 a dependence of the carbon dioxide content in the gas phase versus $\mathrm{pH}$ can be calculated (Figure 8). More details about the dependence obtained will be given in a next contribution. 


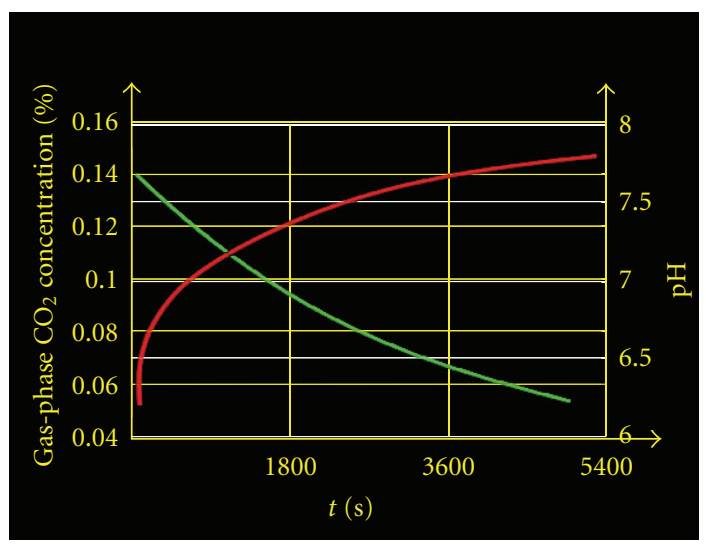

FIgURE 6: Change in $\mathrm{CO}_{2}$ concentration and $\mathrm{pH}$ value versus time, in RI chamber caused by transport through the BMM.

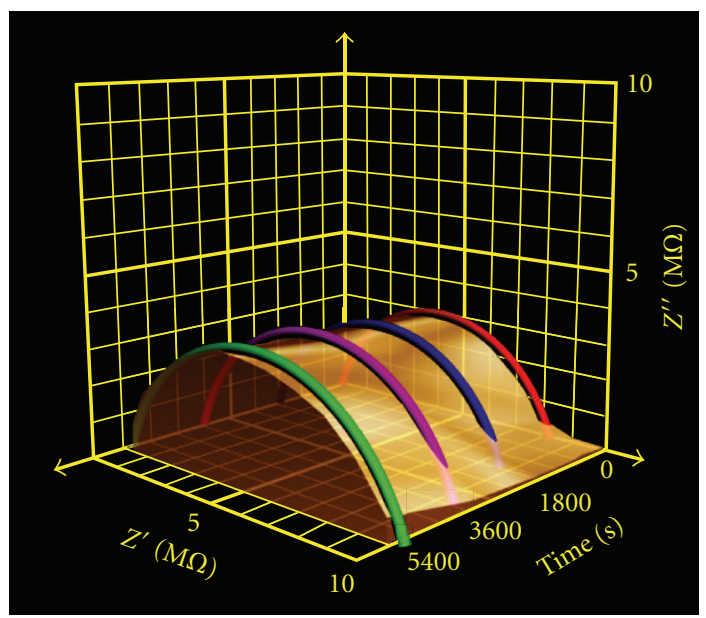

FIGURE 7: Nyquist plot of the millipore membrane (pore diameter $8 \mu \mathrm{m}$ ) impregnated with $320 \mathrm{mg} / \mathrm{mL}$ lecithine in tetradecane versus time: (1) $t=0 \mathrm{~s}$ (beginning of the experiment), (2) $t=1800 \mathrm{~s}$ (30 min), (3) $t=3600 \mathrm{~s}$ (60 min), and (4) $t=5400 \mathrm{~s}$ (90 min; after the end of the experiment). The BMM impedance remains over $3 \mathrm{M} \Omega$. This means that the BMM is intact.

The as-constructed experimental setup was checked with additional impedance measurements of dense cristobalite ceramic discs with a thickness of $2 \mathrm{~mm}$. From the impedance spectra of the ceramic discs, prepared in our laboratory using a sol-gel procedure, pressing and heating at $1300^{\circ} \mathrm{C}$ [17], we calculated the dielectric constant of $\beta$-cristobalite discs $\varepsilon \approx 4.5$ at $100 \mathrm{kHz}$ which is in good agreement with the data published for quartz $[18,19]$. For this measurement a special capacitive cell with Au-electrodes was constructed. The calculations of $\varepsilon$ were performed by removing the impedance spectra of the empty capacitive cell from that the ceramic discs.

\section{Conclusions}

The $\mathrm{CO}_{2}$ transport through natural membranes such as alveoli barrier membrane systems can be quantitatively

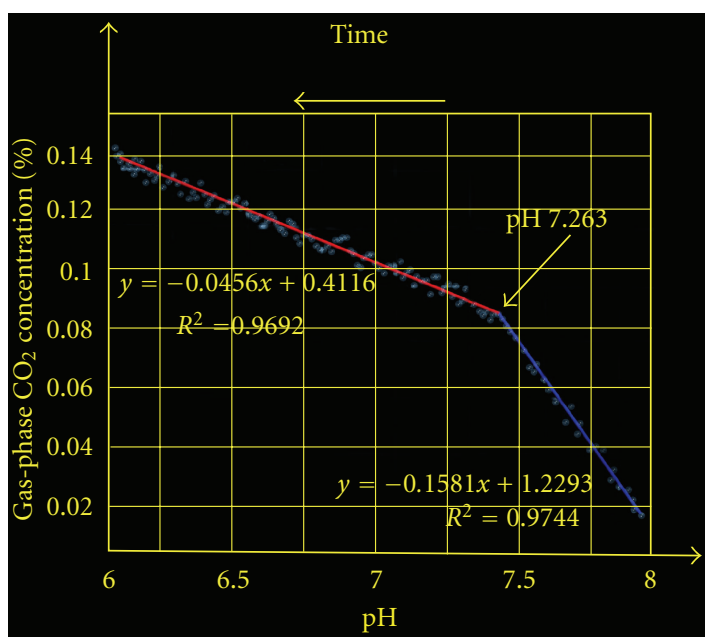

FIGURE 8: Experimentally proved $\mathrm{pH}$ dependence of the $\mathrm{CO}_{2}$ gasphase concentration.

described by electrochemical measurements combined with $\mathrm{pH}$ measurements and a non-dispersive infra-red gas analyzer. We proved experimentally that the $\mathrm{CO}_{2}$ transport through BMM under different conditions depends on $\mathrm{pH}$. The demonstrated electrochemical setup allows an additional check of the membrane integrity using impedance spectra measurements during the gas transport and also can be applied for solid-state measurements for dielectric constant measurements.

\section{Acknowledgments}

Thanks are due to I. Dzhenev, V. Venkov, and M. Minkova for experimental help.

\section{References}

[1] E. Matsaridis, "Application potential of polymer-based membranes," Annuaire de l'Université "St. Kliment Ohridski", vol. 99, pp. 103-120, 2006.

[2] E. Matsaridis, K. Beev, and V. Savov, "Ion selective electrode for ascorbic acid with biomimetic impregnated nitroacetatecellulose ultrafilter membrane," in Proceedings of the Meetings in Physics at University of Sofia, vol. 3, pp. 49-54, 2002.

[3] E. Matsaridis, K. Beev, and V. Savov, "Impregnated ultrafilter membrane electrode for uric acid in biological fluids," Annual of St. Kliment Ohridski University of Sofia, Faculty of Physics, vol. 95, pp. 56-62, 2002.

[4] N. M. Kocherginsky, Liu K. K., and H. M. Swartz, Biofunctional Membranes, Plenum Press, New York, NY, USA, 1996.

[5] N. M. Kocherginsky, Yu. Sh. Moshkovsky, I. S. Osak, and L. A. Piruzian, "The model of biological membrane for the investigation of biologically active compounds," Author Certificate (Patent) USSR no. 1043564, 1983.

[6] A. Ilani, "Frequency-dependent capacitance of hydrophobic membranes containing fixed negative charges," Biophysical Journal, vol. 8, no. 5, pp. 556-574, 1968.

[7] E. Shohami and A. Ilani, "Model hydrophobic ion exchange membrane," Biophysical Journal, vol. 13, no. 11, pp. 12421260, 1973. 
[8] Y. Kobatake, A. Irimajiri, and N. Matsumoto, "Studies of electric capacitance of membranes. I. A model membrane composed of a filter paper and a lipid analogue," Biophysical Journal, vol. 10, no. 8, pp. 728-744, 1970.

[9] M. Yoshida, Y. Kobatake, M. Hashimoto, and S. Morita, "Studies of electric capacitance of membranesII. Conformational change in a model membrane composed of a filter paper and a lipid analogue," The Journal of Membrane Biology, vol. 5, no. 2, pp. 185-199, 1971.

[10] N. M. Kocherginsky, I. S. Osak, L.E. Bromberg, V. A. Karyagin, and Y. S. Moshkovsky, "The modeling of biological membrane properties by means of filters impregated with lipid like substances," Journal of Membrane Science, vol. 30, pp. 39-46, 1987.

[11] R. B. Gennis, Biomembranes: Molecular Structure and Function, Springer, 1989.

[12] B. Alberts, A. Johnson, D. Bray et al., Molecular Biology of the Cell, Garland Publishing, New York, NY, USA, 2002.

[13] H. Lodish, A. Berk, P. Matsudaira et al., Molecular Cell Biology, 5th, W. H. Freeman and Company, New York, NY, USA, 2003.

[14] D. L. Nelson and M. M. Cox, Lehninger Principles of Biochemistry, W. H. Freeman and Company, New York, NY, USA, 2005.

[15] N. M. Kocherginsky, L. E. Bromberg, and G. S. Leskin, "Permeability of impregnated filters to oxygen and carbon dioxide," Russian Journal of Physical Chemistry, vol. 61, pp. 838-842, 1987.

[16] N. M. Kocherginsky and V. F. Lvovich, "Biomimetic membranes with aqueous nano chanels but without proteins: impedance of impregnated cellulose ester filters," Langmuir, vol. 26, no. 23, pp. 18209-18218, 2010.

[17] O. San and C. Ösgür, "Investigation of a high stable $\beta$ cristobalite ceramic powder from $\mathrm{CaO}-\mathrm{Al}_{2} \mathrm{O}_{3}-\mathrm{SiO}_{2}$ system," Journal of the European Ceramic Society, vol. 29, no. 14, pp. 2945-2949, 2009.

[18] H. Stöcker, Ed., Taschenbuch der Physik, Thun, Frankfurt am Main, Germany, 1994.

[19] S. Gutzov, G. Ahmed, N. Petkova, E. Füglein, and I. Petkov, "Preparation and optical properties of samarium doped solgel materials," Journal of Non-Crystalline Solids, vol. 354, no. 29, pp. 3438-3442, 2008. 


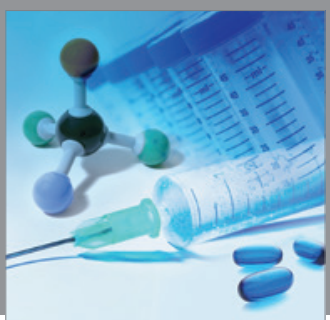

International Journal of

Medicinal Chemistry

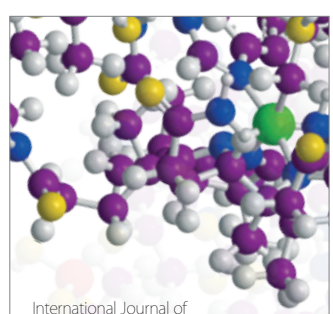

Carbohydrate Chemistry

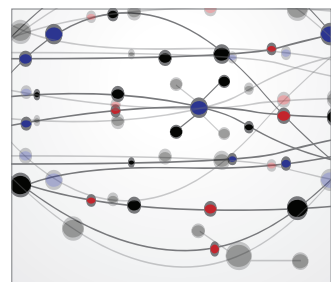

The Scientific World Journal
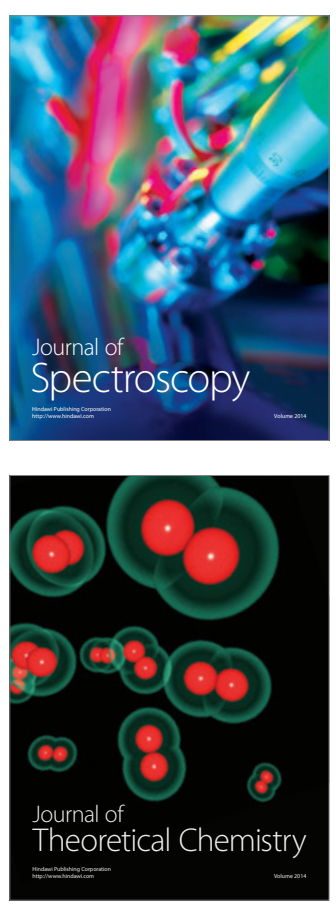
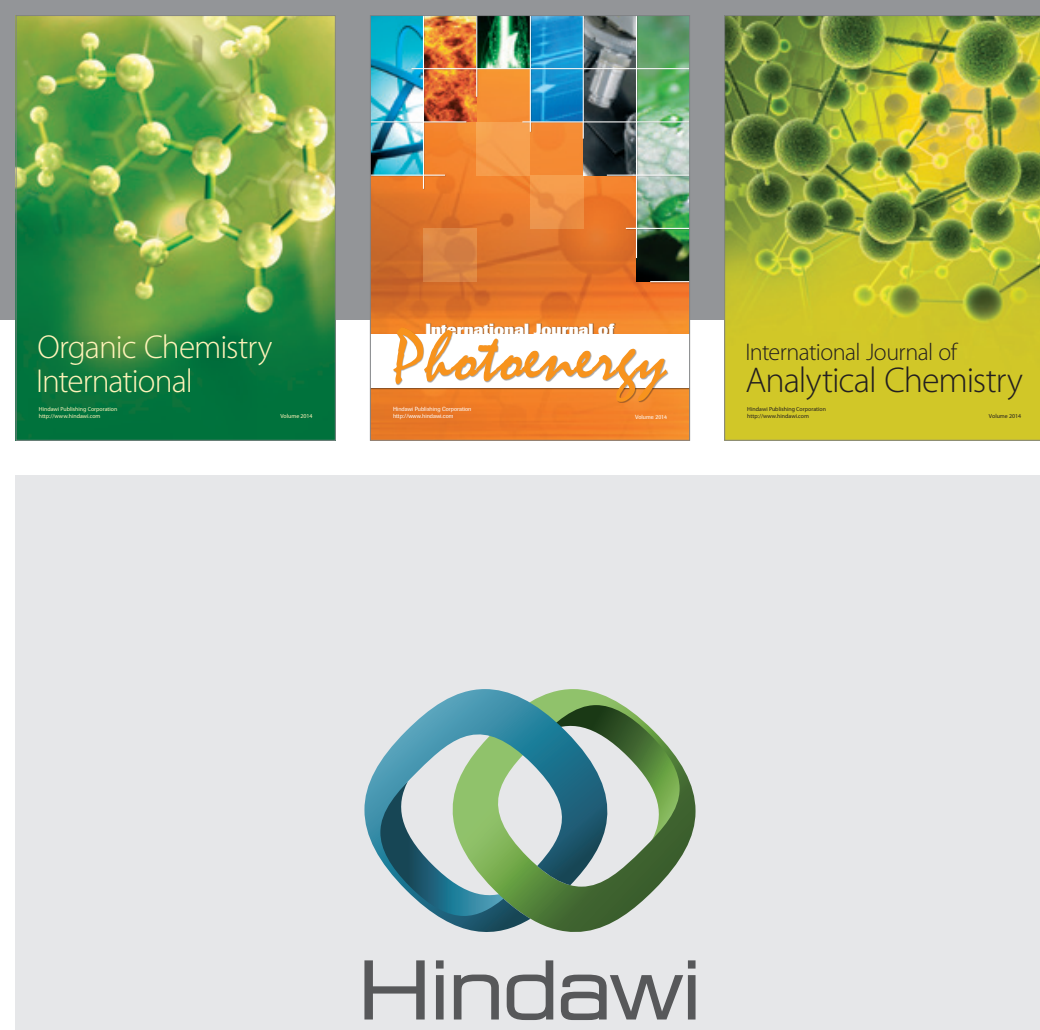

Submit your manuscripts at

http://www.hindawi.com
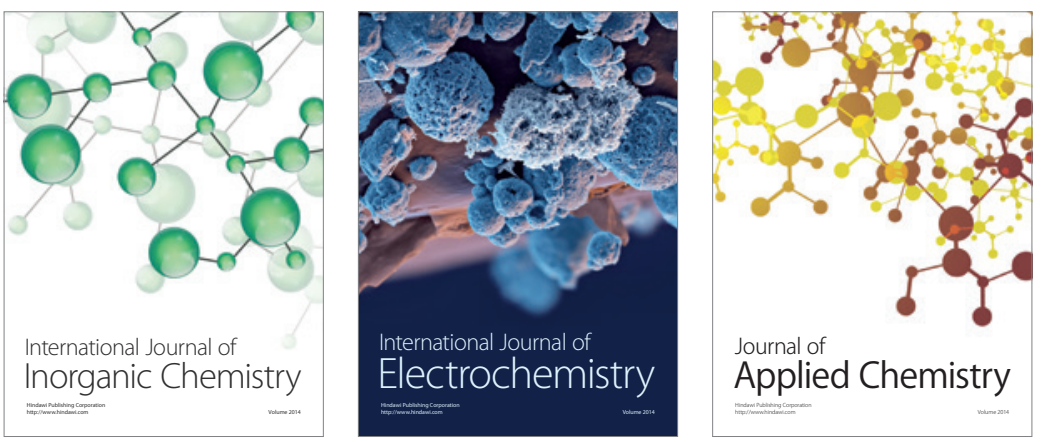

Journal of

Applied Chemistry
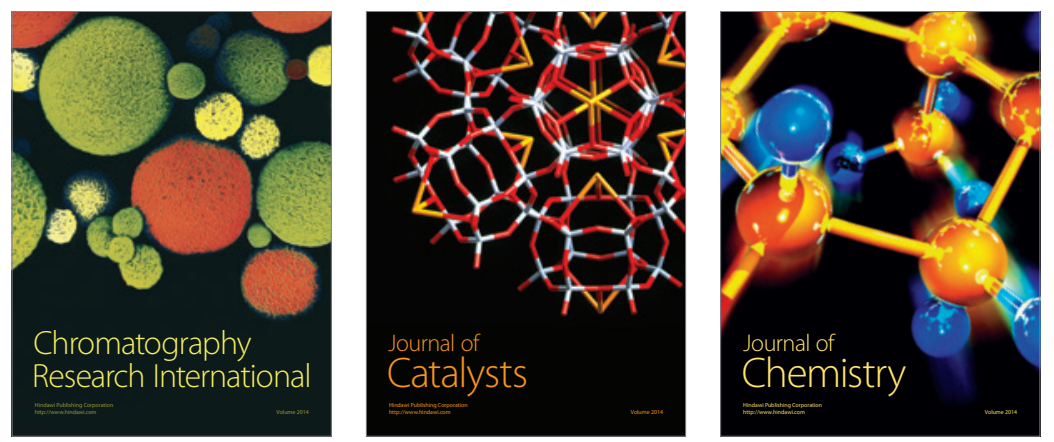
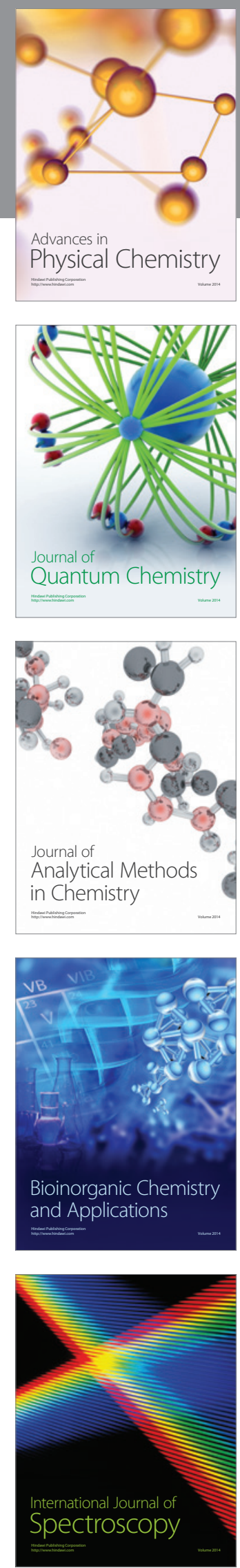